and subsequently incubated them with LY (9). To examine the effect of PPMP on the LY channel or transporter activity in the infected red cell membrane, we incubated trophozoite- and schizontinfected red cells with LY (9) in the presence or absence of $5 \mu \mathrm{M}$ PPMP. The dye could be detected in both treated and control cells, indicating that PPMP does not block the channel or transporter activity at the infected red cell membrane.

13. A. M. Gero, E. M. A. Bugledich, A. R. P. Paterson, G. P. Jamieson, Mol. Biochem. Parasitol. 27, 159 (1988).

14. PPMP-treated and control cells were adjusted to $2 \times$ $10^{7} \mathrm{cell} / \mathrm{s} / \mathrm{ml}$ and incubated with a $1 \mu \mathrm{Ci} / \mathrm{ml}$ concentration of [ ${ }^{3} \mathrm{H}$ ]adenosine $(34.5 \mathrm{Ci} / \mathrm{mmol}$ at a final concentration $29 \mathrm{nM})$ or $\left[{ }^{3} \mathrm{H}\right]$ thymidine $(2 \mathrm{Ci} / \mathrm{mmol}$ at a final concentration of $500 \mathrm{nM}$ ) in phosphate-buffered saline (PBS). Because of its low specific activity, the extracellular concentration of [ ${ }^{3} \mathrm{H}$ ]thymidine was 16 times as high as that of adenosine. For the accumulation of orotic acid, infected erythrocytes treated with $5 \mu \mathrm{M}$ PPMP (10 to $20 \%$ parasitemia) were washed free of serum and adjusted to $5 \times 10^{9}$ cells/ $\mathrm{ml}$ in RPMl 1640. Transport was initiated by mixing equal volumes $(330 \mu \mathrm{l})$ of the cell suspension and [3H]orotic acid at a concentration of $0.26 \mu \mathrm{Ci} / \mathrm{ml}(13$ $\mathrm{Ci} / \mathrm{mmol}$ at a final concentration of $10 \mathrm{nM}$ ). For the accumulation of glutamate, control and PPMP-treated infected red cells were adjusted to $2.5 \times 10^{8}$ cells $/ \mathrm{ml}$ and incubated with $\left[{ }^{3} \mathrm{H}\right]$ glutamate at a concentration of $1 \mu \mathrm{Ci} / \mathrm{ml}(53 \mathrm{Ci} / \mathrm{mmol}$ at a final concentration of $19 \mathrm{nM}$ ) in PBS. For all accumulation assays, the cells were collected by centrifugation through a layer of dibutylphthalate, and the cell pellets lysed, bleached, neutralized, and counted. PPMP treatment had no effect on the uptake of any radiolabeled compound into uninfected red cells. The incorporation of adenosine and orotic acid into nucleic acids was measured as follows. Infected red cells treated with PPMP $(5 \mu \mathrm{M})$ for 12 hours and their corresponding controls were seeded into microtiter plates at $2 \%$ hematocrit and $5 \%$ parasitemia. The cells were incubated in RPMI 1640 containing 10\% human serum and $0.86 \mu \mathrm{Ci} /$ well $(11 \mathrm{nM})$ of [ $\left.{ }^{3} \mathrm{H}\right]$ adenosine or $0.125 \mu \mathrm{Ci} /$ well $(48 \mathrm{nM})$ of [ $\left.{ }^{3} \mathrm{H}\right]$ orotic acid in the presence or absence of $(5 \mu \mathrm{M})$ PPMP for 24 hours at $37^{\circ} \mathrm{C}$. All incorporation assays were carried out in the absence of NBMPR. For glutamate, infected red cells treated for 12 hours with PPMP $(5 \mu \mathrm{M})$ and their corresponding controls were incubated for 24 hours at $37^{\circ} \mathrm{C}$ in RPMl 1640 lacking glutamate and supplemented with $2 \%$ human serum and ${ }^{3} \mathrm{H}$ ]glutamic acid $(20 \mu \mathrm{Ci} / \mathrm{ml}, 377 \mathrm{nM})$.

15. J. L. Crary and K. Haldar, Mol. Biochem. Parasitol. 53, 185 (1992)

16. B. C. Elford, G. M. Cowman, D. J. P. Ferguson, Biochem. J. 308, 361 (1995).

17. H. G. Elmendorf, J. D. Bangs, K. Haldar, Mol. Biochem. Parasitol. 52, 215 (1992)

18. P. K. Rathod, A. Khatri, T. Hubbert, W. K. Milhous, Antimicrob. Agents Chemother. 33, 1090 (1989)

19. Determination of the $\mathrm{IC}_{50}$ of $5-\mathrm{FO}$ in TVM-arrested cells by hypoxanthine incorporation was carried out by plating infected red cells in microtiter dishes at $1 \%$ hematocrit and $1 \%$ parasitemia. [ $\left.{ }^{3} \mathrm{H}\right] \mathrm{H}$ ypoxanthine $(0.5 \mu \mathrm{Ci} /$ well $)$ was added, and the cells were incubated for another 24 hours and then harvested on glass fiber filters (8). Because PPMP reduces the accumulation of exogenous [ $\left.{ }^{3} \mathrm{H}\right]$ hypoxanthine (but does not inhibit the parasite's machinery for nucleic acid synthesis), a separate $\mathrm{IC}_{50}$ plot for 5-FO was determined at $0,0.03,0.3$, and $3.3 \mu \mathrm{M}$ PPMP. At 0 to $0.3 \mu \mathrm{M}$ PPMP, the $1 \mathrm{C}_{50}$ was $6.0 \times 10^{-8} \mathrm{M}$. At $3.3 \mu \mathrm{M}$ PPMP (which corresponds to complete inhibition of the SSS and the TVM), the $\mathrm{IC}_{50}$ of 5 -FO was $7.5 \times 10^{-7} \mathrm{M}$. As expected, saponin abrogated the effects on nucleoside uptake. Determination of the $\mathrm{IC}_{50}$ in TVM-arrested cells by Giemsa staining was carried out with infected red cells at $2 \%$ parasitemia and $5 \%$ hematocrit. Cells were subsequently washed free of both PPMP and 5-FO and the parasites were allowed to grow in RPMl 1640 for another 48 hours, at which time parasitemia was determined by Giemsa staining. The $\mathrm{IC}_{50}$ of doxycline (in the absence or presence of PPMP) was $1 \times 10^{-6} \mathrm{M}$. These experiments were carried out as those described for 5 -FO.

20. K. Kirk, H. A. Horner, B. C. Elford, J. C. Ellory, C. Newbold, J. Biol. Chem. 269, 3339 (1994).

21. B. Pouvelle et al., Nature 353, 73 (1991).

22. T. F. Taraschi and E. Nicholas, Parasitol. Today 10 , 399 (1994).

23. S. A. Desai, D. J. Krogstad, E. W. McClesky, Nature 362, 643 (1993).

24. J. R. Swedlow, J. W. Sedat, D. A. Agard, Cell 9, 97 (1993).

25. We thank W. I. Li, J. McBride, D. Taylor, and R. Coppel for antibodies to the $45-\mathrm{kD}$ cleft protein,
Exp1, HRP1, HRP2, and PfEMP2; A. A. Holder for knob-forming FCB strain of $P$. falciparum; R. R. Kopito and S. Mayor for comments on the manuscript; and S. Palmieri and J. VanWye for assistance with the Delta Vision microscope and work station. Supported by NIH grants (Al26670 and Al39071 to K.H., Al26912 and Al01112 to P.K.R.), the MacArthur Foundation (S.L.), and Burroughs Wellcome Fund Awards (New Investigator and New Initiatives in $\mathrm{Ma}$ laria to $\mathrm{K} . \mathrm{H}$.).

13 August 1996; accepted 21 March 1997

\title{
Engineering Chemical Reactivity on Cell Surfaces Through Oligosaccharide Biosynthesis
}

\author{
Lara K. Mahal, Kevin J. Yarema, Carolyn R. Bertozzi*
}

Cell surface oligosaccharides can be engineered to display unusual functional groups for the selective chemical remodeling of cell surfaces. An unnatural derivative of $\mathrm{N}$-acetylmannosamine, which has a ketone group, was converted to the corresponding sialic acid and incorporated into cell surface oligosaccharides metabolically, resulting in the cell surface display of ketone groups. The ketone group on the cell surface can then be covalently ligated under physiological conditions with molecules carrying a complementary reactive functional group such as the hydrazide. Cell surface reactions of this kind should prove useful in the introduction of new recognition epitopes, such as peptides, oligosaccharides, or small organic molecules, onto cell surfaces and in the subsequent modulation of cell-cell or cell-small molecule binding events. The versatility of this technology was demonstrated by an example of selective drug delivery. Cells were decorated with biotin through selective conjugation to ketone groups, and selectively killed in the presence of a ricin A chain-avidin conjugate.

Cell surface molecules govern many biological events such as cell growth and differentiation, communication among different cells, recognition of soluble factors, and attachment to, or disengagement from, the extracellular matrix. Technology that orchestrates the presentation of chemically defined epitopes on a cell surface would enable direct intervention in these biological processes. We present a strategy for remodeling the cell surface in a chemically defined way by exploiting the substrate promiscuity of oligosaccharide biosynthetic pathways. The natural metabolic processes of the cell were used to introduce a reactive functional group, the ketone, into cell surface-associated sialic acid residues. The ketone group is virtually absent from cell surfaces in that none of the naturally occurring amino acids, glycoconjugates, or lipids contains a ketone group, and it can be chemoselectively ligated with hydrazide, hydroxylamino, and thiosemicarbazide groups under physiological conditions (1-5). Thus, the ketone provides a molecular handle for the attachment of biomolecules or small molecular probes to cells. Because the display of

$\overline{\text { Department of Chemistry, University of California, Berke- }}$ ley and Center for Advanced Materials, Materials Sciences Division, Lawrence Berkeley National Laboratory, Berkeley, CA 94720, USA. ketone groups is achieved solely through the action of the biosynthetic machinery, this process constitutes a practical method to engineer the composition of the cell surface in vivo.

Sialic acids are appropriate vehicles for cell surface functional group display because (i) they are the most abundant terminal components of oligosaccharides on mammalian glycoproteins and glycolipids, and (ii) the enzymes that participate in sialic acid metabolism are permissive for simple unnatural substrates (6-10). Sialic acids are biosynthesized from the six-carbon precursor $N$-acetylmannosamine (ManNAc) $(11,12)$. Reutter and coworkers have demonstrated that unnatural mannosamine derivatives, in which the $N$-acetyl group of ManNAc was substituted with $N$-propanoyl, $N$-butanoyl, or $N$ pentanoyl, are converted to the corresponding sialosides and incorporated into glycoconjugates in cell culture and in rats $(13,14)$. These observations suggest that all components of the cellular machinery involved in sialoside biosynthesis can tolerate unnatural acyl substituents.

Accordingly, we synthesized N-levulinoyl mannosamine (ManLev) (Fig. 1A), which has the ketone functionality at the position normally occupied by the $N$-acetyl group in the natural substrate 
ManNAc. We selected three human cell lines-Jurkat ( $T$ cell-derived), HL-60 (neutrophil-derived), and HeLa (cervical epithelial carcinoma) - to test the biosynthetic conversion of ManLev to the corresponding cell surface-associated, unnatural sialic acid (Fig. 1A). Cells were treated with ManLev, and the presence of ketone groups on the cell surface was determined by the chemoselective ligation of a hydrazide-based probe, biotinamidocaproyl hydrazide (Fig. 1B). The cells were analyzed by flow cytometry after being stained with FITC (fluorescein isothiocyanate) avidin (15). The Jurkat, HL-60, and HeLa cells treated with ManLev showed a large increase in fluorescence intensity compared to cells treated with buffer or the natural derivative ManNAc (Fig. 2). ManLev-treated cells that were stained with FITC-avidin alone, without prior biotinamidocaproyl hydrazide treatment, showed only a background fluorescence. These results indicate that ManLev-treated cells express cell surface-associated ketone groups and can be chemoselectively decorated with hydrazide conjugates even in the presence of serum.

We performed a series of experiments to demonstrate that the ketone groups are displayed on the cell surface in the form of modified sialoglycoconjugates. Jurkat cells were treated with tunicamycin, an inhibitor of $\mathrm{N}$-linked protein glycosylation, before incubation with ManLev $(16,17)$. We anticipated a dramatic reduction in ketone expression on the basis of the observation that most mature (and therefore sialylated) oligosaccharides on Jurkat cells are found on $\mathrm{N}$ linked rather than O-linked glycoproteins (18). Indeed, ketone expression resulting from ManLev treatment was inhibited by tunicamycin in a dose-dependent fashion (Fig. 3A), suggesting that the ketone groups are presented on oligosaccharides and are not nonspecifically associated with cell surface components. In contrast, ketone expression in HL-60 and HeLa cells was unaffected by tunicamycin, but was instead blocked by $\alpha$-benzyl $N$-acetylgalactosamine, an inhibitor of O-linked glycosylation, consistent with the high expression of mucin-like molecules on myeloid- and epithelial-derived cell lines.

Although we predicted that ManLev would be converted into the corresponding sialoside, we addressed the possibility that ketone expression resulted from conversion of ManLev to N-levulinoyl glucosamine (GlcLev) by the enzyme that interconverts ManNAc and GlcNAc (12). In that GlcNAc is incorporated into most glycoproteins, GlcLev might have many avenues for cell surface expression. Flow cytometry revealed only a background lev- el of fluorescence, suggesting that unnatural sialosides are the major biosynthetic products of ManLev.

Ideally, proof of the cell surface expression of ketone-bearing sialic acids would involve abrogating the fluorescence signal by treatment with sialidase enzymes. However, the commercially available sialidases were found to be inactive against $N$-levulinoyl sialosides, in accordance with their known reduced activity against sialosides with other unnatural $N$-acyl groups (19). We therefore evaluated the effects of ManLev treatment on the amount of normal sialic acid on Jurkat cells, expecting a reduction. Indeed, the amount of sialic acid released from ManLev-treated cells by sialidase digestion, as quantified by high $\mathrm{pH}$ anion exchange chromatography (HPAEC), was approximately 10 times lower than that released from ManNActreated cells $(13,20)$.

There are two possible explanations for the observed reduction in normal sialic acid on ManLev-treated cells: (i) normal sialic acid is replaced with the unnatural sialic acid during incubation with ManLev, or (ii) the biosynthesis of all sialosides is suppressed during incubation with ManLev. Inhibition of sialoside biosynthesis would cause an increase in exposed terminal galactose residues, the penultimate residue in the majority of sialoglycoconjugates. We therefore examined the effect of ManLev

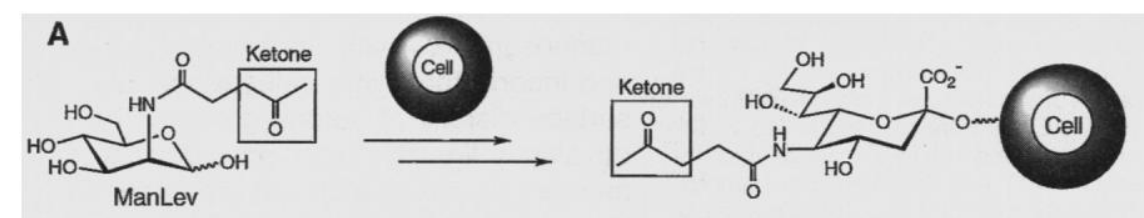

B

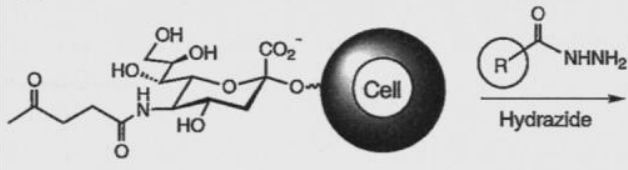

Fig. 1. Biosynthetic incorporation of ketone groups into cell surface-associated sialic acid. (A) N-Levulinoyl mannosamine (ManLev, ML) is metabolically converted to the corresponding cell surface sialoside. (B) Cells displaying ketone groups can be chemoselectively ligated to hydrazides under physiological conditions through the formation of an acyl hydrazone. Cell surface ketones were conjugated to biotinamidocaproyl hydrazide to provide a tag for subsequent detection with FITC-avidin. In principle, any hydrazide-derivatized molecule can be used to selectively remodel the surface of ketone-expressing cells.

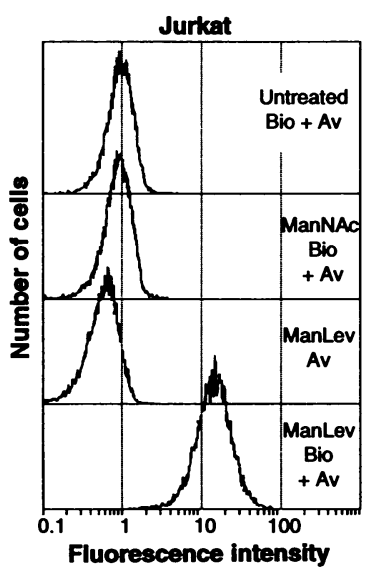

(arbitrary units)

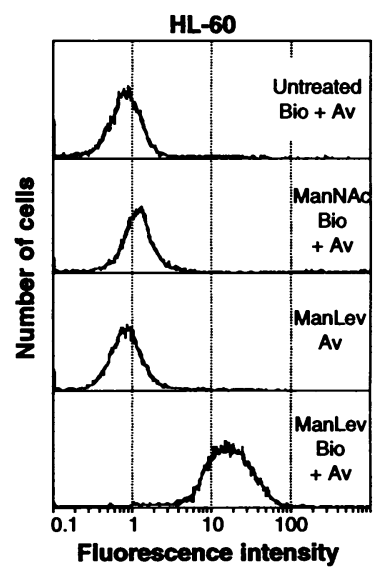

(arbitrary units)

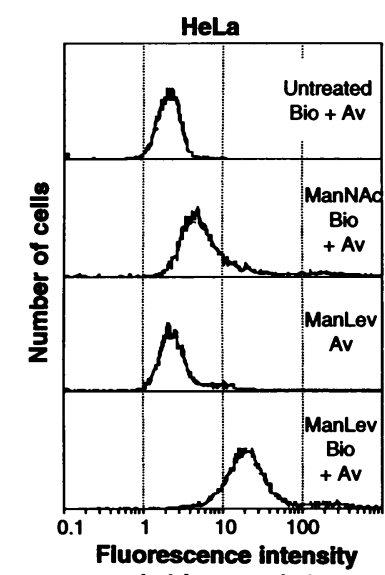

(arbitrary units)

Fig. 2. Ketone expression in Jurkat, $\mathrm{HL}-60$, and HeLa cells. Cells treated with buffer alone or with ManNAc showed only background fluorescence. Cells treated with ManLev showed up to a 30-fold increase in fluorescence above background. The fluorescence increase was dependent on both biotinamidocaproyl hydrazide (Bio) and FITC-avidin (Av) treatment. Results were similar in three replicate experiments for each cell line. 
treatment on the binding of the galactosespecific lectin ricin to Jurkat cells (21). Ricin binding to ManLev-treated and untreated cells was identical (Fig. 3B), an indication that ManLev treatment does not inhibit sialoside biosynthesis. Sialidase treatment of normal Jurkat cells increased ricin binding over background as expected (22). When ManLev-treated cells were digested with sialidase, however, a much smaller increase in ricin binding was ob- served. This finding is consistent with the substitution of normal sialic acids with unnatural sialic acids refractory to enzymatic cleavage in ManLev-treated cells.

We have also determined the quantitative and physiological limits to the cell surface expression of ketone groups. Ketone expression is dose-dependent and saturable in ManLev-treated Jurkat cells (Fig. 3C). At saturation, we calculated the number of ketones accessible to chemoselective liga-
Fig. 3. Ketone groups are expressed within cell surface sialic acids. (A) Tunicamycin inhibits ketone incorporation in a dose-dependent fashion, confirming the presence of ketones on $\mathrm{N}$-linked oligosaccharides (17). Identical results were obtained in three replicate experiments. (B) Ricin binding of normal and ManLevtreated Jurkat cells with and without sialidase treatment. Ricin binding was quantified by staining with FITC-RCA 120 (Sigma) followed by analysis by flow cytometry (22). Error bars represent the standard deviation of the mean for three replicate experiments. (C) Ketone incorporation into cell surface sialo-

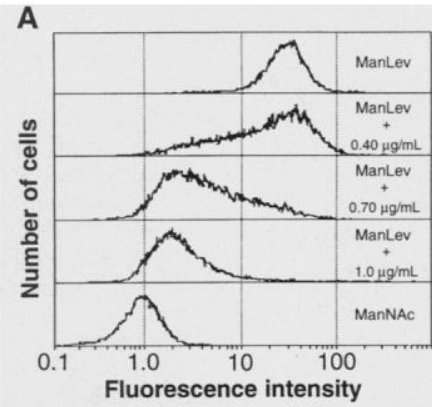
(arbitrary units)

C

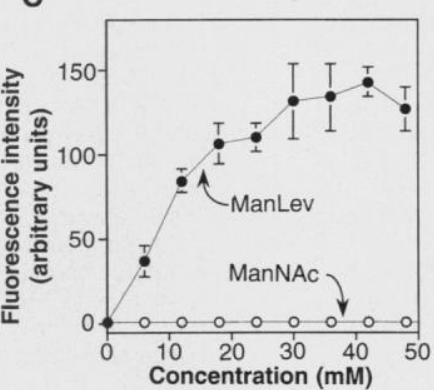

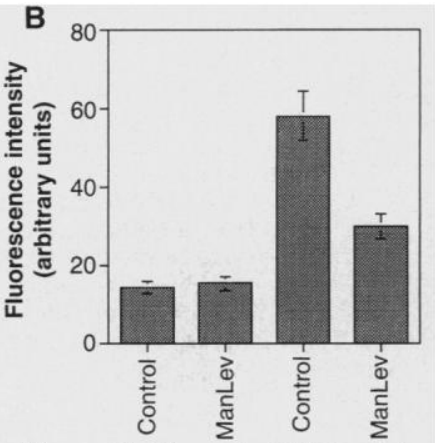

D
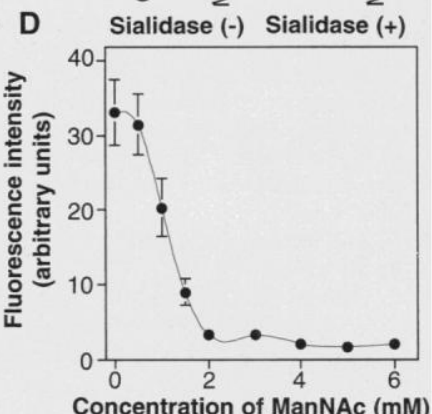

sides is dose-dependent and saturable. Jurkat cells were incubated with increasing concentrations of ManLev or ManNAc for 48 hours, stained with Bio and Av, and analyzed by flow cytometry. Data from four experiments is shown. (D) ManNAc competes with ManLev and inhibits ketone incorporation. Jurkat cells were incubated with ManLev $(5 \mathrm{mM})$ and increasing concentrations of ManNAc for 48 hours, and ketone expression was quantified by flow cytometry. Each data point represents the average from three experiments and error bars represent the standard deviation of the mean. tion and flow cytometry analysis to be approximately $1.8 \times 10^{6}$ per cell (23). No effects on cell morphology or the rate of cell growth were observed during prolonged (up to 6 weeks) treatment with ManLev. We therefore conclude that even at maximal levels, the presence of sialic acid-associated ketones does not grossly alter normal cellular function. In addition, we demonstrated that metabolism of ManLev was inhibited by simultaneous addition of ManNac, confirming that both substrates compete in the same biosynthetic pathway (Fig. 3D).

Our ability to manipulate the chemical reactivity of cell surfaces with biosynthetic processes opens the door to a myriad of applications. Sialic acid residues are overexpressed on a number of human cancers (24), offering the expression of unnatural, reactive sialic acids as a possible mechanism to differentiate cancer cells from normal cells in a new targeting strategy. Cell surfaces can be engineered to present unusual epitopes for the selective targeting of drugs, radionuclides or imaging reagents, an alternative to wellknown immunotargeting strategies.

We have demonstrated the viability of this approach with biotin hydrazide as a chosen cell surface epitope for the delivery of avidinconjugated toxins (Fig. 4A). We chose the ricin toxin A chain (RTA), a potent inhibitor of protein synthesis, as a model toxin on the basis of precedents in the field of immunotoxin research $(25,26)$ and, accordingly, we prepared a disulfide-linked RTA-avidin conjugate by known methods $(27,28)$. The disulfide linkage provides a mechanism for toxin release once the cell surface-bound conjugates enter the reducing environment of the interior of the cell $(29,30)$.

The selective toxicity of the RTAavidin conjugate was evaluated with Jurkat cells treated with varying concentrations of
Fig. 4. A method for engineering unusual cell surface epitopes for selective drug delivery. (A) Cells were treated with ManLev resulting in the expression of cell surface ketones. Reaction with biotin hydrazide resulted in the display of a specified molecular target on the cell surface, and a ricin $A$ chain-avidin conjugate selectively targeted biotin-modified cells. (B) Toxicity of the RTA-avidin conjugate against Jurkat cells treated with varying concentrations of ManLev. Jurkat cells were grown with (or without) ManLev and labeled with biotin-hydrazide in PBS containing $5 \%$ NCS as described earlier. The cells were washed and resuspended in PBS $(\mathrm{pH} 7.4,0.1 \%$ NCS) at a density of $5 \times 10^{5}$ cells $/ \mathrm{ml}$. Cells $(100 \mu \mathrm{l})$ were added to $100 \mu \mathrm{l}$ of RTA-avidin diluted to various concentrations in PBS with $0.1 \%$ NCS. The
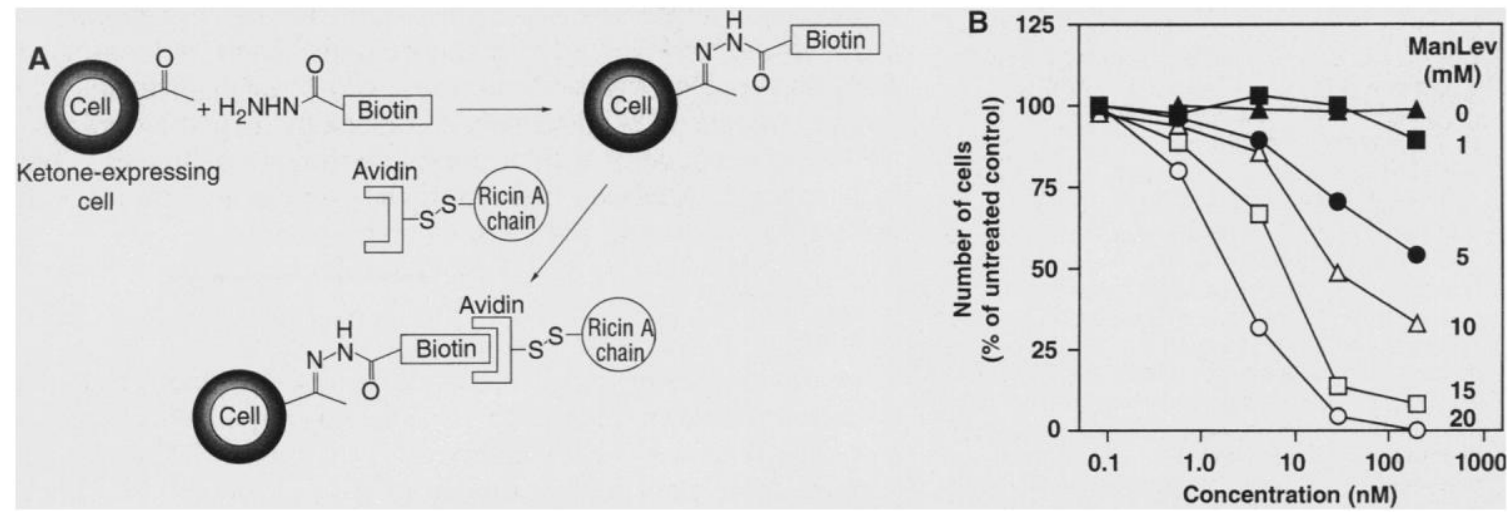

cells were incubated for $15 \mathrm{~min}$ at room temperature, and then washed twice to remove excess RTA-avidin. The cells were resuspended in $1.0 \mathrm{ml}$ of media (RPMl-1640 with 5\% FCS) and incubated for 3 days. The numbers of living and dead cells were determined by Trypan blue staining and then by counting a minimum of 500 cells per sample under a light microscope. Similar results were obtained in three separate experiments. 
ManLev and then decorated with biotin hydrazide (Fig. 4B). The toxicity of the conjugate was dependent on the expression of ketones: Cells expressing high levels of ketones $(>700,000$ ketones per cell as estimated by flow cytometry analysis) were sensitive to the conjugate with lethal doses $\left(\mathrm{LD}_{50}\right)$ in the range of 1 to $10 \mathrm{nM}$. In contrast, the conjugate showed no toxicity against cells expressing fewer ketones $(<50,000$ ketones per cell). These results indicate that cell surfaces can be metabolically engineered to support selective drug delivery, and that the sensitivity of target cells can be controlled by modulating the expression level of the unique targeting epitope.

Variations of this strategy can be envisioned, such as the direct targeting of cell surface ketones with hydrazide-conjugated drugs or probes and the use of other mutually reactive organic functional group pairs. The chemoselective formation of hydrazone linkages among small molecule pro-drugs has been accomplished in whole animals and human subjects (4), setting the precedent for the application of cell surface engineering in vivo. Other potential applications of cell surface remodeling include engineering new determinants for immunological recognition, tissue-specific cell trafficking, and cell adhesion to synthetic substrates.

\section{REFERENCES AND NOTES}

1. K. Rose, J. Am. Chem. Soc. 116, 30 (1994).

2. L. E. Canne, A. R. Ferré-D'Amaré, S. K. Burley, S. B. H. Kent, ibid. 117, 2998 (1995).

3. D. Rideout, T. Calogeropoulou, J. Jaworski, M. McCarthy, Biopolymers 29, 247 (1990).

4. D. Rideout, Cancer Invest. 12, 189 (1994).

5. J. Shao and J. P. Tam, J. Am. Chem. Soc. 117, 3893 (1995).

6. R. E. Kosa, R. Brossmer, H.-J. Gross, Biochem. Biophys. Res. Commun. 190, 914 (1993)

7. W. Fitz and C.-H. Wong, J. Org. Chem. 59, 8279 (1994).

8. S. L. Shames et al., Glycobiology 1, 187 (1991).

9. M. A. Sparks et al., Tetrahedron 49, 1 (1993).

10. C.-H. Lin, T. Sugai, R. L. Halcomb, Y. Ichikawa C. -H. Wong, J. Am. Chem. Soc. 114, 10138 (1992).

11. L. Warren, Bound Carbohydrates in Nature (Cambridge Univ. Press, New York, 1994).

12. A. Varki, FASEB J. 5, 226 (1991)

13. H. Kayser et al., J. Biol. Chem. 267, 16934 (1992).

14. O. T. Keppler et al., ibid. 270, 1308 (1995).

15. Cultures ( $2 \times 10^{6}$ cells) were grown in media containing ManLev (5 mM), ManNAc, or no sugar for 48 hours. Cells were then washed twice with biotinstaining buffer $[0.1 \%$ newborn-calf serum (NCS) in phosphate-buffered saline (PBS), $\mathrm{pH}$ 6.5] and resuspended at a density of $10^{7}$ cells $/ \mathrm{ml}$. Portions ( 2 $\times 10^{6}$ cells) were suspended in $1.4 \mathrm{ml}$ of biotin staining buffer and $400 \mu$ of biotinamidocaproyl hydrazide ( $5 \mathrm{mM}$ solution in PBS, Sigma) or $400 \mu \mathrm{l}$ of buffer. After 2 hours at room temperature, the cells were centrifuged and washed twice with icecold avidin staining buffer $\left(0.1 \% \mathrm{NaN}_{3}, 0.1 \%\right.$ NCS in PBS, $\mathrm{pH}$ 7.4). The cells were then suspended in $100 \mu l$ of FITC-avidin-staining solution (of FITC avidin at $5.6 \mu \mathrm{g} / \mathrm{ml}$ in avidin-staining buffer). After a 10-min incubation in the dark at $0^{\circ} \mathrm{C}$, the cells were diluted with $2 \mathrm{ml}$ of cold avidin staining buffer and washed twice. The cells were resuspended in 400

$\mu l$ of avidin staining buffer and subjected to flow cytometry analysis.

16. F. M. Ausubel, Ed., Current Protocols in Molecular Biology, vol. 2 (Wiley, New York, 1994).

17. Cultures of $2 \times 10^{6}$ Jurkat cells were grown in $9 \mathrm{ml}$ of media containing varying amounts of a $1 \mathrm{mg} / \mathrm{ml} \mathrm{so}$ lution of tunicamycin in ethyl alcohol $(4.5,7.0$, and $10.0 \mu l)$. After 24 hours, $1 \mathrm{ml}$ of a $50-\mathrm{mM}$ solution of ManLev was added. After an additional 48 hours, the cells were washed twice with biotin buffer $(0.1 \%$ NCS in PBS, pH 6.5) and resuspended at a density of $10^{7}$ cells $/ \mathrm{ml}$. Cells were prepared for flow cytometry analysis as described in (15)

18. V. Piller, F. Piller, M. Fukuda, J. Biol. Chem. 265 9264 (1990)

19. R. Drzeniek, Histochem. J. 5, 271 (1973).

20. B. Potvin, T. S. Raju, P. Stanley, J. Biol. Chem. 270 30415 (1995).

21. G. L. Nicolson, J. Blaustein, M. E. Etzler, Biochemistry 13, 196 (1974)

22. Jurkat cells were grown in the presence and absence of ManLev (20 mM) for 72 hours. Cells $(2 \times$ $10^{5}$ per sample) were washed and resuspended in $0.9 \mathrm{ml}$ of sialidase buffer $(20 \mathrm{mM}$ Hepes, $140 \mathrm{mM}$ $\mathrm{NaCl}, \mathrm{pH}$ 6.8). Sialidase (Clostridium perfringes $100 \mathrm{mU}$ in $100 \mu \mathrm{l})$ or sialidase buffer $(100 \mu \mathrm{l})$ was added to the cells, which were then incubated at $37^{\circ} \mathrm{C}$ for $30 \mathrm{~min}$. The cells were centrifuged and washed with PBS (pH 7.4), and resuspended in 0.5 ml of $25 \mathrm{nM}$ FITC-labeled Ricinus communis agglutinin (FITC-RCA $A_{120}$, Sigma). Cells were incubated on ice with the FITC-RCA 120 for $15 \mathrm{~min}$, washed twice with PBS (pH 7.4), and analyzed by flow cytometry.

23. The relation between fluorescence intensity ob served by flow cytometry analysis and the number of fluorescent molecules per cell were determined with biotinylated polystyrene beads (Spherotech) with a predetermined number of biotin molecules per bead and with a similar diameter to that of Jurkat cells.

24. S. Sell, Human Pathol. 21, 1003 (1990), and references therein

25. L. Barbieri, M. G. Battelli, F. Stirpe, Biochim. Biophys. Acta 1154, 237 (1993)

26. J. M. Lord, L. M. Roberts, J. D. Robertus, FASEB J. 8, 201 (1994)

\title{
Localization of Xenopus Vg1 mRNA by Vera Protein and the Endoplasmic Reticulum
}

\author{
James O. Deshler, ${ }^{*}$ Martin I. Highett, ${ }^{*}$ Bruce J. Schnapp $†$
}

In many organisms, pattern formation in the embryo develops from the polarized distributions of messenger RNAs (mRNAs) in the egg. In Xenopus, the mRNA encoding Vg1, a growth factor involved in mesoderm induction, is localized to the vegetal cortex of oocytes. A protein named Vera was shown to be involved in Vg1 mRNA localization. Vera cofractionates with endoplasmic reticulum (ER) membranes, and endogenous Vg1 mRNA is associated with a subcompartment of the ER. Vera may promote mRNA localization in Xenopus oocytes by mediating an interaction between the $\mathrm{Vg} 13^{\prime}$ untranslated region and the ER subcompartment.

$\mathrm{O}_{\text {ne function of mRNA localization is to }}$ restrict translation of specific mRNAs to particular domains of early embryos $(1,2)$, thereby conferring the beginnings of pattern formation. Vg1 mRNA encodes a

Department of Cell Biology, Harvard Medical School, 240 Longwood Avenue, Boston, MA 02115, USA

*These authors contributed equally to this work.

$\dagger$ †o whom correspondence should be addressed. transforming growth factor $-\beta$ involved in mesoderm induction (3) and is localized to the vegetal blastomeres of early Xenopus embryos (4). Localization of Vg1 mRNA begins in late stage II oocytes where Vg1 mRNA accumulates in a wedge-shaped region of the vegetal hemisphere (5) before being transported to the vegetal cortex of stage III oocytes by a microtubule-dependent process $(5,6)$. Localization is directed 